As stated, quality encompasses a range of processes. Care of the patient is now a shared responsibility of stakeholders who have equal discretionary authority to make care decisions. The pathway to excellence likely involves elements of care that are not well archived and therefore not well studied. How, then, does an institution achieve excellence? The answer lies in a willingness to engage in new paradigms of processes and relationships. These certainly include, among others: elimination of competition between surgeons and subspecialization of procedures performed, open dialogue with team cardiologists during a preoperative conference, preoperative involvement of appropriate consultants for at risk patients, administration supportive of additional inpatient days spent attaining maximal medical optimization, use of a limited number of cardiac anesthesiologists who are accomplished transesophageal echocardiographers equipped with dedicated machines and probes, a care model that encompasses nurse practitioners and intensivists, and a dedicated cardiac quality surveillance team. Clearly, the responsibility for quality extends beyond the surgeon and its pursuit involves a dedicated team effort and supportive, involved administration. Let us commit ourselves to development of the benchmarks needed and a relentless pursuit of excellence in which reducing failure to rescue is seminal.

\section{References}

1. Likosky DS, Strobel RJ, Wu X, Kramer RS, Hamman BL, Brevig JK, et al. the National Cardiac Surgery Quality IMPROVE Network; Interhospital failure to rescue after coronary artery bypass grafting. J Thorac Cardiovasc Surg. 2023; 165:134-43.e3.

2. Jacobs JP, O'Brien SM, Pasquali SK, Jacobs ML, Lacour-Gayet FG, Tchervenkov CI, et al. Variation in outcomes for benchmark operations: an analysis of the Society of Thoracic Surgeons Congenital Heart Surgery database. Ann Thorac Surg. 2011;92:2184-92.

3. Pasquali SK, He X, Jacobs JP, Jacobs ML, O’Brien SM, Gaynor JW. Evaluation of failure to rescue as a quality metric in pediatric heart surgery: an analysis of the STS Congenital Heart Surgery database. Ann Thorac Surg. 2012;94:573-80.

4. Edwards FH, Ferraris VA, Kurlansky PA, Lobbdell KW, He X, O’Brien SM, et al. Failure to rescue rates after coronary artery bypass grafting: an analysis from the Society of Thoracic Surgeons Adult Cardiac Surgery database. Ann Thorac Surg. 2016:102:458-64.

5. Ghaferi AA, Birkmeyer JD, Dimick JB. Variation in hospital mortality associated with inpatient surgery. N Engl J Med. 2009;361:1368-75.

6. Silber JH, Williams SV, Krakauer H, Schwartz JS. Hospital and patient characteristics associated with death after surgery: a study of adverse occurrence and failure to rescue. Med Care. 1992;30:615-29.

7. Ghaferi AA, Birkmeyer JD, Dimick JB. Complications, failure to rescue, and mortality with major inpatient surgery in Medicare patients. Ann Surg. 2009;250:1029-34.

8. Silber JH, Rosenbaum PR, Schwartz JS, Ross RN, Williams SV. Evaluation of the complication rate as a measure of quality of care in coronary artery bypass graft surgery. JAMA. 1995;274:317-23.

\title{
Commentary: Failure to rescue: What does it really measure?
}

\section{Jeffrey P. Jacobs, MD, ${ }^{a}$ David M. Shahian, MD, ${ }^{b}$ Thomas M. Beaver, MD, MPH, ${ }^{\mathrm{a}}$ Eric Y. Pruitt, MD, ${ }^{\mathrm{a}}$ and Fred H. Edwards, MD}

Likosky and colleagues ${ }^{1}$ are to be congratulated for another meaningful contribution to the art and science of outcomes

\footnotetext{
From the ${ }^{a}$ Division of Cardiovascular Surgery, Department of Surgery, University of Florida, Gainesville, Fla; ' Division of Cardiac Surgery, Department of Surgery, Massachusetts General Hospital, Harvard Medical School, Boston, Mass; and ${ }^{\mathrm{c} S h a n d s ~ J a c k s o n v i l l e, ~ U n i v e r s i t y ~ o f ~ F l o r i d a ~ C o l l e g e ~ o f ~ M e d i c i n e ~ J a c k s o n v i l l e, ~}$ Jacksonville, Fla.

Disclosures: The authors reported no conflicts of interest.

The Journal policy requires editors and reviewers to disclose conflicts of interest and to decline handling or reviewing manuscripts for which they may have a conflict of interest. The editors and reviewers of this article have no conflicts of interest.

Received for publication Jan 29, 2021; revisions received Jan 29, 2021; accepted for publication Jan 29, 2021; available ahead of print Feb 5, 2021.

Address for reprints: Jeffrey P. Jacobs, MD, Division of Cardiovascular Surgery, Department of Surgery, Congenital Heart Center, University of Florida, 1600 SW Archer Rd, Gainesville, FL 32608 (E-mail: JeffJacobs@msn.com).

J Thorac Cardiovasc Surg 2023;165:146-8 $0022-5223 / \$ 36.00$

Copyright $(2021$ Published by Elsevier Inc. on behalf of The American Association for Thoracic Surgery

https://doi.org/10.1016/j.jtcvs.2021.01.129
}

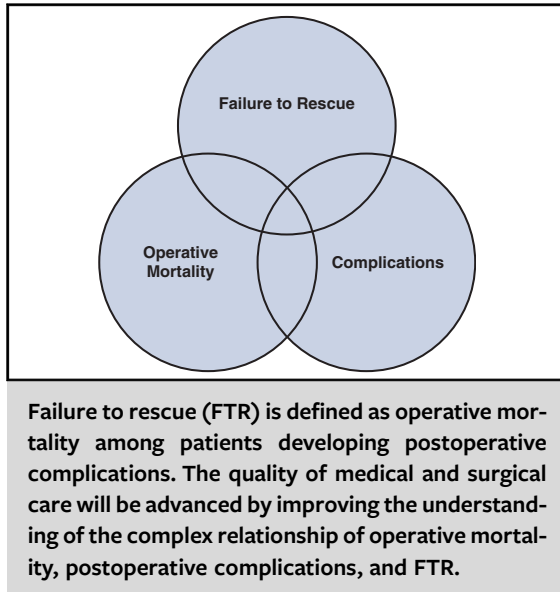

CENTRAL MESSAGE

Failure to rescue (FTR) is defined as operative mortality among patients developing postoperative complications. As a measure of quality, FTR will allow for more focused assessment of postoperative cardiothoracic surgical care. 
analysis and quality improvement in cardiothoracic surgery. Failure to rescue (FTR) is defined as operative mortality among patients developing postoperative complications. Operative mortality is defined in all Society of Thoracic Surgeons (STS) databases as "(1) all deaths, regardless of cause, occurring during the hospitalization in which the operation was performed, even if after 30 days (including patients transferred to other acute care facilities), and (2) all deaths, regardless of cause, occurring after discharge from the hospital but before the end of the 30th postoperative day.",2,3

In their observational study of 83,747 patients undergoing isolated coronary artery bypass grafting (CABG) operations between July 2011 and June 2017 across 90 hospitals, Likosky and colleagues report that the "significant interhospital variation in mortality rates was driven principally by failure to rescue rates rather than complication rates." They conclude that "the reported interhospital variability in successful rescue following CABG supports the importance of identifying best practices at high-performing hospitals, including early recognition and management of complications," and state that "efforts to reduce mortality should focus on identifying and implementing optimal rescue strategies."

FTR as a measure of quality has been studied using both the Society for Thoracic Surgeons (STS) Congenital Heart Surgery Database (STS CHSD) ${ }^{4}$ and the STS Adult Cardiac Surgery Database (STS ACSD). ${ }^{5}$ Pasquali and colleagues ${ }^{4}$ examined FTR in STS CHSD and concluded that "hospitals with low mortality rates do not have fewer complications after pediatric heart surgery, but instead have lower mortality in those who experience a complication (lower FTR). Further investigation into FTR as a quality metric in pediatric heart surgery is warranted". Edwards and colleagues ${ }^{5}$ examined FTR in STS ACSD and concluded that "CABG mortality rates vary directly with FTR, but complication rates have little relation to death. FTR rates derived from The Society of Thoracic Surgeons data can serve as national benchmarks. Predicted FTR rates may facilitate patient counseling, and FTR O/E ratios have promise as valuable quality metrics."

A risk model is a mathematical formula that can be used to predict the probability that a given outcome will occur, ${ }^{6}$ typically based on data from a large benchmark population. Whenever one is developing or using a risk model, it is important to consider the purpose of the analysis. Risk models can be used to predict the risk of a given patient, assess the case mix of a given program, or even assess the performance of a given program in comparison with multi-institutional aggregate outcome data. ${ }^{6}$ The point in time at which risk is being assessed with a risk model is critical in each of these applications. The STS Adult Cardiac Surgery Risk Models ${ }^{7,8}$ facilitate estimation of the risk of procedure-specific operative mortality and morbidity adjusted for preoperative patient-level factors present at the time that the patient enters the operating theater. The STS CHSD Mortality Risk Model similarly facilitates estimation of the risk of operative mortality adjusted for preoperative patient-level factors present at the time that the patient enters the operating theater. ${ }^{9-11}$

Risk adjustment for FTR requires a somewhat different time frame. To better estimate risk at the time that the patient enters the intensive care unit (ICU) after surgery, and to focus on performance of the postoperative care team and ICU, FTR risk models should include intraoperative and early postoperative parameters that are present on arrival to the ICU, such as cardiopulmonary bypass time, aortic cross-clamp time, and postoperative arterial blood levels of lactate immediately on arrival to the ICU. Thus, the resulting risk-adjusted outcomes would account not only for the patient's original preoperative risk factors, but also for events during the procedure (eg, excessive blood loss, long cross-clamp times) that may contribute to risk. The inclusion of such intraoperative risk factors and immediate postoperative risk factors reflects the condition of the patient at the completion of the operation, and also reflects the overall risk of the patient when their care is assumed by the postoperative care team. Therefore, the inclusion of such intraoperative risk factors and immediate postoperative risk factors facilitates more accurate estimation of risk-adjusted FTR.

Likosky and colleagues are to be congratulated for enhancing our understanding of FTR. As the assessment of cardiothoracic surgical quality evolves, it is important to include all phases of delivery of healthcare. Cardiothoracic surgeons are involved in, and ultimately responsible for, all phases of cardiothoracic surgical care, including preoperative assessment and optimization, intraoperative management, and postoperative care. As a complement to overall risk-adjusted rates of operative mortality and morbidity, FTR will facilitate a more focused assessment of the quality of postoperative cardiothoracic surgical care, specifically the ability to salvage patients who experience serious postoperative complications.

\section{References}

1. Likosky DS, Strobel RJ, Wu X, Kramer RS, Hamman BL, Brevig JK, the National Cardiac Surgery Quality IMPROVE Network; Interhospital failure to rescue after coronary artery bypass grafting. J Thorac Cardiovasc Surg. 2023; 165:134-43.e3.

2. Jacobs JP, Mavroudis C, Jacobs ML, Maruszewski B, Tchervenkov CI, LacourGayet FG, et al. What is operative mortality? Defining death in a surgical registry database: a report from the STS congenital database task force and the joint EACTS-STS congenital database committee. Ann Thorac Surg. 2006;81: $1937-41$.

3. Overman DM, Jacobs JP, Prager RL, Wright CD, Clarke DR, Pasquali SK, et al. Report from the Society of Thoracic Surgeons national database work force: clarifying the definition of operative mortality. World J Pediatr Congenit Heart Surg. 2013;4:10-2. 
4. Pasquali SK, He X, Jacobs JP, Jacobs ML, O'Brien SM, Gaynor JW. Evaluation of failure to rescue as a quality metric in pediatric heart surgery: an analysis of the STS congenital heart surgery database. Ann Thorac Surg. 2012;94:573-9; discussion 579-80.

5. Edwards FH, Ferraris VA, Kurlansky PA, Lobdell KW, He X, O'Brien SM, et al. Failure to rescue rates after coronary artery bypass grafting: an analysis from the Society of Thoracic Surgeons adult cardiac surgery database. Ann Thorac Surg. 2016;102:458-64.

6. Jacobs JP. Risk models for congenital and pediatric cardiac care: the importance of timing of data collection and selection of outcome variables. J Thorac Cardiovasc Surg. 2017;154:629-30.

7. Shahian DM, Jacobs JP, Badhwar V, Kurlansky PA, Furnary AP, Cleveland JC Jr, et al. The Society of Thoracic Surgeons 2018 adult cardiac surgery risk models, part 1: background, design considerations, and model development. Ann Thorac Surg. 2018;105:1411-8.
8. O'Brien SM, Feng L, He X, Xian Y, Jacobs JP, Badhwar V, et al. The Society of Thoracic Surgeons 2018 adult cardiac surgery risk models, part 2: statistical methods and results. Ann Thorac Surg. 2018;105:1419-28.

9. O'Brien SM, Jacobs JP, Pasquali SK, Gaynor JW, Karamlou T, Welke KF, et al. The Society of Thoracic Surgeons congenital heart surgery database mortality risk model, part 1: statistical methodology. Ann Thorac Surg. 2015;100:1054-62.

10. Jacobs JP, O’Brien SM, Pasquali SK, Gaynor JW, Mayer JE Jr, Karamlou T, et al The Society of Thoracic Surgeons congenital heart Surgery database mortality risk model, part 2: clinical application. Ann Thorac Surg. 2015;100:1063-8; discussion 1068-70.

11. Jacobs JP, O'Brien SM, Hill KD, Kumar SR, Austin EH III, Gaynor JW, et al Refining the Society of Thoracic Surgeons congenital heart surgery database mortality risk model with enhanced risk adjustment for chromosomal abnormalities, syndromes, and noncardiac congenital anatomic abnormalities. Ann Thorac Surg. 2019;108:558-66. 